\title{
Análise da dependência dos municípios do Vale do Rio Pardo aos recursos de transparência do FPM
}

\author{
Analysis of dependence of the municipalities os Vale do Rio Pardo/RS FPM transfer resources
}

\author{
Mariangela Ravanello', Reisoli Filho Bender"
}

\begin{abstract}
Resumo
O momento de instabilidade econômica está interferindo diretamente na arrecadação dos impostos de todos os entes federados, impactando duplamente nos municípios, tanto nas receitas próprias como nas receitas oriundas das transferências constitucionais, principalmente do Fundo de Participação dos Municípios (FPM), que chega a representar 70\% da arrecadação. Esse cenário subsidiou o objetivo de analisar o nível de dependência dos recursos de transferência do FPM comparativamente a arrecadação própria do COREDE Vale do Rio Pardo, no período de 2009 a 2016. Metodologicamente, trata-se de pesquisa descritiva, de cunho quali-quantitativo, com método de abordagem analítico-comparativo. Em termos de resultados, os municípios foram estratificados conforme faixa populacional em três grupos distintos: municípios de pequeno e médio porte, com população inferior a 50.000 habitantes; atividade econômica pouco expressiva, basicamente rural; alto grau de dependência do FPM, média de 28 e $41 \%$ respectivamente no período e; de grande porte, com população superior a 50.000 habitantes, que constitui-se de municípios mais estruturados economicamente, apresentando uma relação inversa de dependência do FPM, com média no período de 15\%. Ademais, observou-se elevado crescimento na arrecadação nos anos de 2010 e 2014, motivados por emendas parlamentares e por transferências de capital do governo federal.
\end{abstract}

Palavras-chave: Finanças Municipais; FPM; COREDE Vale do Rio Pardo

\begin{abstract}
The moment of economic instability is interfering directly in the collection of the taxes of all the federated entities, impacting doubly in the municipalities, both in revenue as in revenue from transfers to constitutional, mainly from the Municipal Participation Fund (FPM), which accounts for $70 \%$ of the collection. This scenario subsidized the objective of analyzing the level of dependence of the FPM transfer resources compared to the own collection of COREDE Vale do Rio Pardo, from 2009 to 2016. Methodologically, it is a descriptive research, quantitative-qualitative, with an analytical-comparative approach. In terms of results, the municipalities were stratified according to population range in three distinct groups: groups 2 and 3, with a population of less than 50,000 inhabitants; economic activity little expressive, basically rural; high degree of dependence of the FPM, average of 28 and $41 \%$ respectively in the period, and; the group 1, with a population of over 50,000 inhabitants, which constitute municipalities more structured economically, presenting an inverse relationship of dependence of the FPM, with a mean period of 15\%. In addition, we observed a high growth revenue in the years of 2010 and 2014, motivated by amendments parliamentary and transfers of capital revenue from the federal government.
\end{abstract}

Keywords: Municipal Finance; FPM; COREDE Vale do Rio Pardo

I Universidade Federal de Santa Maria, RS, Brasil - ednalvafelix@gmail.com 


\section{Introdução}

No Brasil, o federalismo fiscal, juntamente com a Constituição Federal de 1988, representaram os marcos à descentralização administrativa, financeira e social dos estados e dos municípios. Nesta construção, o Fundo de Participação dos Municípios (FPM) define-se como uma transferência intergovernamental, constitucional e federal de caráter descentralizador, sendo partilhado de forma diferenciada entre estados federados e os municípios com base no critério da composição populacional. No entanto, a descentralização de recursos fiscais não foi acompanhada de uma correspondente e adequada transferência de responsabilidades aos governos estaduais e locais. Conforme discussão apresentada por Teixeira (2005), o resultado dessa inadequação entre recursos e responsabilidades resultou na deterioração dos serviços públicos.

$\mathrm{Na}$ condição de principais executores das políticas públicas, os municípios precisam atender demandas que evoluem rapidamente e cada vez exigem mais qualidade e opções de serviços. Nesta perspectiva, os municípios deparam-se com o desafio de discutir a capacidade de satisfatoriamente atender as crescentes demandas da sociedade, especialmente nas áreas de saúde e educação, ao mesmo tempo em que enfrentam os desafios da eficiência, eficácia e efetividade na gestão dos escassos recursos públicos.

$\mathrm{Na}$ contramão, a situação econômica vem agravando-se ano após ano, sobremaneira após 2009 com a implementação de inúmeras ações do governo federal para contornar a crise e fomentar a economia brasileira, como as desonerações do Imposto sobre Produtos Industrializados (IPI) de veículos e da linha branca, que refletiu diretamente na baixa arrecadação do FPM. Essa transferência caracteriza-se como a principal receita para o equilíbrio dos orçamentos municipais, representando mais de $70 \%$ das receitas orçamentárias dos municípios (FINBRA, 2012). Bremaeker (2011 apud SANTOS, 2014) ratifica que, para 81\% dos municípios, o FPM é a principal fonte de recursos.

Situação não diferente é encontrada no Conselho Regional de Desenvolvimento (COREDE) Vale do Rio Pardo, na região central do Rio Grande do Sul. Conforme Petry e Silveira (2017), essa região apresenta elevada heterogeneidade em termos geográficos, socioeconômicos e fiscais. Todavia, o cenário demonstra ser mais grave nos municípios menores, caso de $92 \%$ dos que compõem o COREDE, classificados em geral no nível médio de dependência de transferências constitucionais, dependência entre $20 \%$ e $50 \%$. Situação que demonstra a necessidade de os municípios buscarem alternativas à expansão de suas receitas, pois, no que se refere às transferências dos entes federais e estaduais, a retração tem sido sistêmica nos últimos anos.

Além disso, as dificuldades financeiras do COREDE Vale do Rio Pardo estão associadas também à falta de controle fiscal, comum aos pequenos municípios, restringindo a execução de projetos necessários à população, diminuindo com isso a qualidade dos serviços prestados. Entretanto, para dar continuidade ao funcionamento dos serviços públicos básicos, os municípios adotaram medidas de contenção, como implementação turno único, corte de horas extras e diárias, redução de gastos publicitários, demissão de cargos de confiança e comissionados, além da redução de algumas atividades de manutenção. (FAMURS, 2016).

Este cenário engendra a discussão sobre o equilíbrio fiscal municipal e fundamenta a problemática: qual o nível de dependência dos recursos de transferência do FPM e qual a dinâmica orçamentária dos municípios do COREDE Vale do Rio Pardo, considerando o período 2009-2016? Objetivamente, propõe-se analisar a estrutura orçamentária dos municípios do COREDE do Vale do Rio Pardo, no período de 2009 à 2016, discutindo a evolução e a dependência da transferência do FPM. A isso, soma-se o atual cenário da gestão pública, com problemas econômicos, financeiros, sociais e políticos que têm tornado constantes as manifestações por melhorias na aplicação e alocação dos recursos públicos. Ainda, destaca-se que esta proposta busca contribuir com o escasso arcabouço analítico sobre finanças públicas municipais, porém de relevância impar à efetiva implementação de políticas públicas fortalecendo a estrutura fiscal dos municípios.

Além desta introdução, o texto está estruturado em outras quatro seções. Na segunda apreenderá conceitos sobre: Administração Pública, Planejamento e Orçamento Público, e entendimentos sobre a arrecadação pública; na sequência, terceira seção, detalha-se a metodologia utilizada; na quarta apresentam-se os resultados alcançados e; por fim, a última, delineiam-se as conclusões deste estudo.

\section{Referencial teórico}

\section{Administração pública e o orçamento público}

A Administração Pública, conforme destacado por Kohama (2012), consiste em todo o aparelhamento do Estado, preordenado à realização de seus serviços destinados à satisfação das necessidades coletivas, com a gestão e prestação dos serviços públicos. Os serviços públicos, em particular o municipal, envolve a interpretação de objetivos, a fim de transforma-los em ações por meio do planejamento, da organização, da direção e do controle, e compreende 
o conjunto de ideias, atitudes, normas e processos que determinam a forma de distribuir e de exercer a autoridade política e de atender aos interesses públicos. (MATIAS-PEREIRA, 2012)

Nesta perspectiva, o orçamento público constitui-se no principal instrumento de controle governamental, pois nele é apurado o montante a ser arrecadado a cada ano e como os recursos serão aplicados nas diferentes ações governamentais. Definindo assim, a gestão financeira, a qual se refere aos procedimentos empregados na obtenção e administração dos recursos financeiros necessários para a realização dos serviços públicos e dos programas de interesse local.

Para Matias-Pereira (2012), o orçamento é um instrumento de identificação e avaliação do gasto público, que expressa as necessidades concretas de uma coletividade. É também uma "lei especial" que recebeu tratamento diferenciado na atual constituição brasileira e que tem por objetivo estimar as receitas e autorizar as despesas, pautadas em concepções políticas pré-definidas. Por ser um instrumento que tem sua elaboração e execução regulamentadas, o orçamento público geralmente é tratado como uma peça jurídica e analisado numa perspectiva preponderantemente técnica.

Constata-se que o orçamento possui características próprias em função das leis às quais está atrelado, devendo obedecer a determinados princípios e, em função dos seus objetivos, possui aspectos que se tornam evidentes quando da sua elaboração e execução. Ainda, salienta-se a peculiaridade do orçamento para cada ente, cada município, pois, como enfatiza Silva (2009), é um plano de trabalho governamental expresso em termos monetários que evidencia a política econômico-financeira do governo. Por sua vez, a Lei no 4.320/64 em seu artigo 2o dispõe que: "o orçamento conterá a discriminação da receita e despesa de forma a evidenciar a política econômica financeira e o programa de trabalho do governo, obedecendo aos princípios da unidade, universalidade e anualidade".

Assim, dada a sua importância, o orçamento constitui-se como elemento básico da contabilidade pública. Logo, é fundamental entender a origem do orçamento, saber a legislação que o disciplina, sua definição e objetivos, os princípios orçamentários, o ciclo que envolve o orçamento, seu conteúdo em termos de propostas orçamentárias e principais componentes, em síntese, a constituição da receita e da despesa pública. Na sequência, aborda-se detalhadamente as receitas públicas, ou seja, os recursos que financiam as ações previstas no orçamento.

\section{Instrumentos de arrecadação pública e a repartição de receita}

As receitas públicas, conforme Baião (2013), correspondem ao ingresso de recursos no patrimônio público, que se refletem no aumento das disponibilidades. Corroborando com este entendimento, Kohama (2012) denomina como receita pública todo e qualquer recolhimento aos cofres públicos, e também, a variação ativa, proveniente do direito a receber no momento da ocorrência do fato gerador, quer seja efetuado por meio de numerário ou outros bens representativos de valores. Na interpretação de Jardim (2011), a Lei no 4320, de 17 de março de 1964, que estabeleceu normas de finanças públicas, determina receita como o ingresso de recursos financeiro aos cofres, independente do acréscimo ao patrimônio líquido.

Conceitua-se também, receita, como toda arrecadação de rendas autorizada pela Constituição Federal, leis e títulos creditórios à Fazenda Pública, formando as disponibilidades financeiras para o financiamento das despesas públicas. Neste sentido, faz-se importante ressaltar as competências tributárias entre os entes da federação, como determina a Constituição Federal de 1988, em seu art. 156. De modo que cada ente possua sua competência privativa e exclusiva, vedada a bitributação. Em todas as federações a arrecadação é maior no nível mais amplo e menor nos níveis locais, tornando necessária a transferência de recursos da instância central aos governos subnacionais (REZENDE, 2006).

Porém, a CF/1988 não cria tributos, apenas estabelece as competências de tributação de acordo com o que cada ente pode legislar. O artigo 153 assegura que a União possa instituir impostos sobre a importação de produtos estrangeiros, exportação de produtos nacionais ou nacionalizados, renda e proventos de qualquer natureza, produtos industrializados, operações de crédito, câmbio e seguro, ou relativas a títulos ou valores mobiliários, propriedade territorial rural e grandes fortunas.

Aos Estados e ao Distrito Federal compete instituir impostos sobre transmissão causa mortis e doação, de quaisquer bens ou direitos, operações relativas à circulação de mercadorias e sobre prestação de serviços de transporte interestadual e intermunicipal e de comunicação, ainda que as operações e as prestações se iniciem no exterior, e propriedade de veículos automotores. Já aos Municípios compete instituir impostos sobre propriedade predial e territorial urbana, transmissão "inter vivos", a qualquer título, por ato oneroso, de bens imóveis, por natureza ou acessão física, e de direitos reais sobre imóveis, exceto os de garantia, bem como cessão de direitos a sua aquisição e sob serviços de qualquer natureza.

No que tange aos Municípios, Silva (2009) ressalta que esses entes enfrentam dificuldades na arrecadação tributária, devido a fatores econômicos, administrativos ou políticos, os quais geram desequilíbrios nas finanças públicas. Portanto, mesmo com uma estrutura de competências tributárias definida, existe a necessidade de um sistema de 
transferências intergovernamentais de recursos, com origem nos níveis superiores de governo (União e Estados), voltadas aos níveis inferiores (Municípios).

A transferência, além de corrigir as diferenças entre atribuições e receitas nos diferentes níveis de governo (ou o desequilíbrio vertical na federação), representa uma oportunidade de atenuar as disparidades regionais. Baião (2013) salienta, ainda, que o território de um país raramente é homogêneo do ponto de vista econômico e social. Conforme expresso no Manual da Receita Nacional (2008), as transferências intergovernamentais compreendem a entrega de recursos, correntes ou de capital, de um ente a outro. É importante destacar que essas transferências ocorrem entre esferas distintas de governo, e não guardam relação, portanto, com as operações intraorçamentárias.

No art. 158, a CF/1988 estabelece que pertencem aos Municípios: o produto da arrecadação do imposto da União sobre renda e proventos de qualquer natureza, $50 \%$ do produto da arrecadação do imposto da União sobre a propriedade territorial rural, $50 \%$ do produto da arrecadação do imposto do Estado sobre a propriedade de veículos automotores e vinte e $5 \%$ do produto da arrecadação do imposto do Estado sobre operações relativas à circulação de mercadorias e sobre prestações de serviços de transporte interestadual e intermunicipal e de comunicação (BRASIL, 2013).

No Brasil, devido à desigualdade regional e à grande heterogeneidade e extensão de seu território, as transferências aos governos subnacionais tornam-se ainda mais importantes. Conforme destaca Rezende (2006), um dos desafios do federalismo fiscal tem sido enfrentar a ampliação das disparidades regionais, que concentram as bases tributárias em pontos específicos do território e, consequentemente, afetam a repartição das receitas tributárias entre os entes federativos.

Assim, todas as federações ainda centralizam em algum grau sua arrecadação tributária, apesar da tendência de descentralização verificada em diversos países nas últimas décadas (ABRÚCIO, 2005). Conforme destaca Prado (2007), na totalidade de federações mundiais, os governos dos níveis superiores arrecadam mais do que gastam, enquanto os de níveis inferiores gastam mais do que arrecadam, recebendo assim, o nome de brecha vertical, o que explica o fato de todas as federações fazerem uso de transferências verticais.

A repartição de receitas está estabelecida conforme a Constituição Federal, o Código Tributário e as Leis Complementares; para cada tributo partilhado segue uma regra específica. O FPM é arrecadado pela União, formado pelo Imposto sobre a Renda e Proventos de Qualquer Natureza (IR) e o Imposto sobre Produtos Industrializados (IPI). É partilhado de acordo com a faixa populacional e a renda per capita de acordo com coeficientes individuais definidos pelo Instituto Brasileiro de Geografia e Estatística - IBGE e reconhecido pelo Decreto-Lei Tribunal de Contas da União - TCU nº 1.881/1981.

Igualmente ocorre com o Imposto de Circulação de Mercadorias e Serviços (ICMS), cujo Estado arrecadador partilha 50\% com os municípios conforme coeficiente de distribuição específico. Para apurar esses índices de participação dos Municípios é realizada a média das participações do Valor Adicionado Fiscal (VAF municipal) no Estado, conforme disposto na Lei Estadual 11.038/1997, que dispõe sobre parâmetros que a Constituição Federal incumbe aos Estados e Distrito Federal.

\section{FPM - Fundo de participação dos municípios}

O FPM, é a mais importante transferência de recurso do país, tem por objetivo de rateio amenizar as desigualdades regionais de modo a dar aos Municípios das regiões mais pobres e de menor porte do interior, condições financeiras semelhantes aos de seus congêneres nas regiões mais ricas, de maior porte e de capitais. Pois, além de todas as demandas locais os Municípios devem destinar durante o exercício, nunca menos de $25 \%$ (vinte e cinco por cento) para a educação, e 15\% (quinze por cento) para a saúde, de toda receita de impostos, incluindo as transferências, conforme estabelecido em Lei.

O FPM é o valor repassado pela União aos Estados, Distrito Federal e Municípios brasileiros. O dinheiro repassado é oriundo da arrecadação do Imposto de Renda (25\%) e do Imposto sobre Produtos Industrializados. A Lei 5.172/1966 e Ato complementar 35/1967, mostra que o FPM é uma transferência constitucional e a distribuição dos recursos aos municípios é feita de acordo com fator representativo da população e Fator representativo do inverso da renda per capita do respectivo Estado.

A fixação dos coeficientes individuais de participação dos municípios no FPM é efetuada com base na população de cada município brasileiro - enviadas ao Tribunal de contas do Estado pelo IBGE até o dia 31 de outubro de cada exercício - e na renda per capita de cada estado, que também é informada pelo IBGE. Para os fins do cálculo das quotas referentes aos fundos de participação, o IBGE publica no Diário Oficial da União, até o dia 31 de agosto de cada ano, a relação das populações por estados e municípios.

A parcela do FPM aos municípios elevou-se gradualmente: passou de 17,5\% do produto da arrecadação de IR e IPI para 20,5\% no ano de 1989; para 22,5\% em 1993; e com as Emendas Constitucionais 55/2007 e 84/2014, houve a conquista de um repasse adicional de $1 \%$ em dezembro e $1 \%$ em julho, respectivamente para o ano de 2016 , levando a um percentual total de $24,5 \%$ do produto da arrecadação para o FPM. Mas, de toda a arrecadação nacional, a União 
fica em média com $54 \%$, os Estados, com $26 \%$ e os Municípios apenas $20 \%$, apesar de os últimos serem os Entes que estão mais próximos da população, que prestam o maior número de serviços e concentram mais responsabilidades. (CNM, 2016)

As cidades brasileiras que antes da Constituição tinham uma responsabilidade mais limitada, sendo os serviços prestados ou pela União ou pelos Estados, a partir de 1988, começaram a assumir cada vez mais atribuições, como, por exemplo, as áreas de educação e saúde, as quais foram municipalizadas. Também é fonte adicional de custo os inúmeros Programas Federais, cuja execução vem ficando a cargo das prefeituras com repasses subfinanciados, pesando sobre o orçamento local. Ressalta-se que o FPM, principal fonte de receita de grande parte dos Municípios brasileiros, não acompanhou o crescimento dos custos das prefeituras nos últimos anos, agravando seriamente a dificuldade financeira destes municípios. (CNM, 2017)

\section{Metodologia}

$\mathrm{Na}$ estrutura orçamentária brasileira, os municípios apresentam expressiva heterogeneidade. Os de grande porte, com população superior a 150.000 habitantes, possuem maior capacidade de arrecadar receitas próprias, tais como ISS, IPTU e ITBI. Já os municípios de médio porte, aqueles entre 50 e 150.000 habitantes, dependem mais detidamente do ICMS. Por sua vez, os municípios pequenos, com população abaixo de 50.000 habitantes, dependem quase que integralmente das transferências constitucionais, do Fundo de Participação dos Municípios (FPM), do Fundo de Manutenção e Desenvolvimento da Educação Básica e de Valorização dos Profissionais da Educação (Fundeb), do Imposto Territorial Rural (ITR), Cide Combustível e Royalties.

Considerando essas condições, o COREDE do Vale do Rio Pardo, por apresentar considerável heterogeneidade e para facilitar análise, foi dividido em três grupos conforme faixa populacional e renda, assim definidos: grande porte - municípios com população acima de 50.000; médio porte - população entre 10 e 50.000 habitantes e; pequeno porte - população inferior a 10.000 habitantes. Conforme Santos e Santos (2014), quanto menor o porte demográfico dos municípios, menor é a sua arrecadação tributária, não apenas pelo seu menor quantitativo, mas também pelo fato de que os principais tributos municipais têm sua base de tributação no meio urbano, prevalecendo a característica rural.

O conjunto de variáveis utilizadas compreendeu os anos de 2009 a 2016, período que equivale a duas gestões municipais (ou dois mandatos), o que facilita a análise comparativa e evolutiva dos dados dos entes locais. Têm-se como base de coleta de dados, os sites oficiais: Tribunal de Contas do Estado TCE/RS, sistema FINBRA (Finanças Públicas) e Portal da Transparência dos Municípios. Os dados de fonte secundária permitiram observar a evolução das receitas orçamentárias municipais e a participação das receitas de transferência.

Em termos analíticos, especialmente, avaliou-se a dependência ao principal recurso de transferência federal - o FPM, a partir da relação do montante arrecadado de receita orçamentária de cada município e o repasse recebido no período analisado. Estas informações subsidiaram o cenário em análise por meio do detalhamento quantitativo à discussão, conforme descrição das etapas:

1ํㅡ etapa: realizada breve contextualização dos municípios que compõem o COREDE Vale do Rio Pardo por meio de informações dos sites da Fundação de Economia e Estatística (FEE), da Federação da Associação dos Municípios do Rio Grande do Sul e do Portal da Transparência dos Municípios.

2르 Etapa: realizada pesquisa longitudinal documental levantando informações nos sites oficiais de governo: Tribunal de Contas do Estado TCE/RS, sistema FINBRA (Finanças Públicas) e Portal da Transparência dos Municípios. Faz-se relevante essa coleta, pois o estudo busca identificar a dinâmica das receitas de transferência dos diferentes municípios.

3르 Etapa: calculado o nível de dependência dos municípios no período analisado utilizando como base para a análise a relação entre a Receita Orçamentária Anual de cada município e o repasse recebido constitucionalmente do governo federal relativo ao Fundo de Participação dos Municípios.

$4^{\underline{a}}$ Etapa: utilizados os dados quantitativos para realizar o cruzamento das informações, as quais permitiram estabelecer o comportamento, a evolução da arrecadação no período de tempo analisado. Seguindo esta linha, o nível de dependência dos municípios em relação às transferências do FPM foi calculado a partir da relação entre a Receita Orçamentária Total Anual (RO) arrecadada por cada município e o repasse anual estabelecido constitucionalmente pelo governo federal para o FPM, conforme equações (1) e (2):

Dependência $=\mathrm{FPM} / \mathrm{RO}$

$\%$ Dependência $=$ Dependência* 100

5 Etapa: classificar o nível de dependência dos municípios utilizando como base as definições empregadas por 
Massardis e Abrantes (2016) no estudo "Dependência do FPM dos Municípios de Minas Gerais”: > 50\%: alta dependência; entre $20 \%$ e $50 \%$ : média dependência e; < $20 \%$ : baixa dependência

Os resultados obtidos permitiram mensurar as características comuns ou incomuns ou padrões sobre o nível de dependência dos recursos do Fundo de Participação dos Municípios do COREDE Vale do Rio Pardo no período estudado.

\section{Resultados e análises}

\section{Estrutura orçamentária dos municípios do COREDE Vale do Rio Pardo}

A União, ao longo de 18 anos, ampliou sua participação nos recursos, pois o foco da fiscalização deixou de ser os impostos compartilhados entre os entes federados e passou a ênfase às contribuições, as quais não têm previsão constitucional de rateio. Com isso, a União concentrou parcelas maiores dos quantitativos tributários, caso de 2015, quando $68,2 \%$ do total de impostos arrecadados foram à esfera federal. Por outro lado, as políticas de incentivo ao setor produtivo estão concentradas naqueles impostos sujeitos a repartição tributária, caso do IPI, que inclusive tem sido reduzido, impactando na arrecadação dos municípios.

Com a eclosão da crise mundial em 2008, o governo federal começou a adotar algumas políticas macroeconômicas para manter a economia aquecida e o nível de empregos. Uma das principais medidas adotadas foi a desoneração do IPI para vários setores econômicos. Esta medida macroeconômica acabou acarretando enormes prejuízos aos Fundos Constitucionais, caso do FPM que perdeu entre 2009 e 2014, o valor de R $\$ 11,09$ bilhões, os quais não foram distribuídos entre os municípios (CNM, 2016).

Afora isso, com a recessão econômica, a alta do desemprego e a redução do rendimento real das pessoas ocupadas, as receitas públicas sofreram queda acentuada em 2015 e 2016 . Este cenário impactou diretamente na redução das transferências do ICMS e do FPM de mais $\mathrm{R} \$ 515$ e de $\mathrm{R} \$ 777$ milhões, respectivamente, para os municípios do Rio Grande do Sul, conforme FAMURS (2017). Este resultado equivale a uma queda conjunta no biênio de $21,32 \%$ das transferências de ICMS e de FPM previstas quando comparadas com as arrecadadas nos municípios gaúchos.

Considerando o COREDE Vale do Rio Pardo, a arrecadação dos municípios de pequeno porte, nos anos de 2009 a 2016, apresentou grandes oscilações, variando entre crescimento de até $40 \%$ de um lado e, de outro lado, decréscimo de mais de $10 \%$ nas arrecadações. Deduz-se daí uma conjuntura de instabilidade financeira e necessidade de esforço gerencial para ajustar os orçamentos e manter o cumprimento de metas de resultados entre receitas e despesas, conforme art. $4^{\circ} \S 1^{\circ}$ da Lei de Responsabilidade Fiscal.

Em termos de evolução da arrecadação total, foram registrados nos anos de 2010 e 2014 os maiores crescimentos, os quais foram motivados principalmente por receitas de capital de emendas parlamentares, visto que foram anos eleitorais nas esferas nacional e estadual. Entretanto, nos anos de 2013 e 2015, houve decréscimo da arrecadação total em alguns municípios de pequeno porte, de acordo com o TCE/RS (2017) e com o Portal da Transparência Municipal (2017).

Detalhadamente, a arrecadação total dos municípios com população inferior a 10.000 habitantes, apresentou crescimento médio de aproximadamente $11 \%$, sendo que os maiores aumentos ocorreram em Mato Leitão, Sinimbu e Pântano Grande, respectivamente nos anos de 2010, 2014 e 2016. Para o primeiro município, que obteve acréscimo de 39\% no ano de 2010 (ver Figura 2), a elevação se deveu ao ingresso de "Receitas de Transferência de Capital de Convênios da União e do Estado” à aquisição de ambulância, construção de unidade de saúde, ginásio de esportes, infraestrutura asfáltica, recursos esses que não constavam no orçamento inicial do município.

De igual forma ocorreu nos demais municípios, com o crescimento da arrecadação direcionado para obras de construção e investimentos. Embora as receitas de capital sejam muito importantes para o desenvolvimento municipal, nem sempre significam aporte de recursos para atendimento de demandas sociais locais, as quais o governo deve buscar outras fontes para ancorá-las.

Além disso, para esses municípios, bem como para Estrela Velha, Ibarama e Herveiras, que obtiveram acréscimo na arrecadação no ano de 2010, além de recursos de emendas parlamentares e transferências de capital, receberam recursos dos governos Federal e Estadual devido à situação de emergência e calamidade decorrente das fortes chuvas ocorridas no mês de janeiro do referido ano. Os repasses foram para custear obras de restauração e de recuperação de estradas destruídas por enchentes e inundações.

Já a expansão verificada em 2016 pode ser explicada por meio da Emenda Constitucional n. 84 de 2014 , a qual altera o art. 159 da Constituição Federal para aumentar a entrega de recursos pela União para transferência de FPM, no percentual de 1\%, gradualmente e de forma integral no ano de 2016. Também, nesse ano, o recebimento dos recursos da repatriação e regularização de ativos (bens, valores, créditos e direitos) mantidos no exterior e não declarados, conforme Lei n. 13.254/2016 alterada pela Lei n. 13.428/2017 alavancaram a média da arrecadação. 
Por outro lado, com a eclosão da crise mundial em 2008, o governo federal começou a adotar algumas políticas macroeconômicas expansionistas, como a desoneração do IPI para vários setores econômicos como forma de manter a atividade econômica e o nível de emprego. Todavia, essa política acarretou prejuízos às transferências governamentais, prejudicando diretamente aqueles pequenos municípios que possuem a maior dependência das transferências constitucionais. Isso ocorreu nos municípios de Pantano Grande, Sinimbu, General Câmara, Boqueirão do Leão, Segredo, Mato Leitão, Ibarama, Estrela Velha, Lagoa Bonita do Sul e Herveiras, cuja retração da receita nos anos de 2011, 2013 e 2015 chegou a atingir mais de 10\% (ver Figura 1).

Figura 1 - Evolução da arrecadação dos municípios de pequeno porte, no período de 2009 a 2016, em \%.

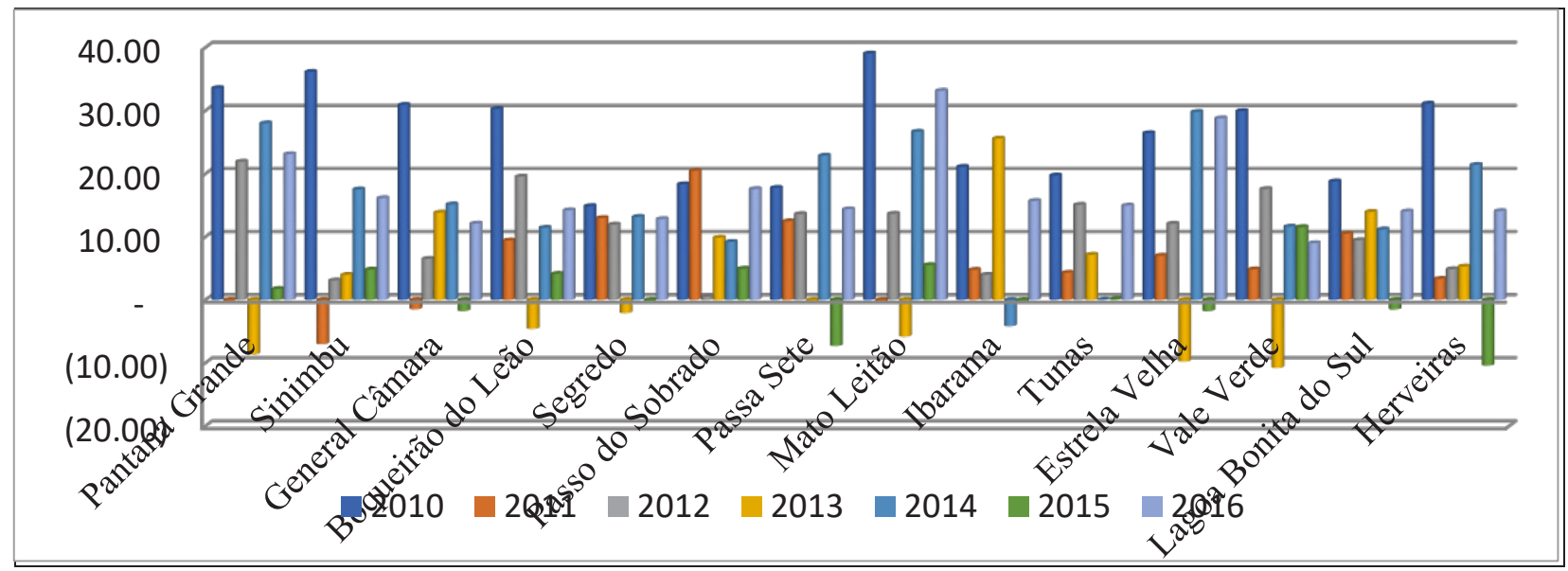

Fonte: Organizada pelos autores, 2017.

Porém, as maiores variações negativas foram verificadas em Vale Verde e Estrela Velha, com quedas de 9,74\% e 10,76\%, respectivamente, em 2013. Essa situação decorreu da baixa capacidade da economia, como também resultou das políticas governamentais de estímulo ao consumo, a partir da promoção de diversas desonerações do IPI, as quais agravaram ainda mais a situação financeira das prefeituras. Neste período foram editados 14 decretos que desoneraram o IPI, medida que impactou diretamente nas finanças municipais, uma vez que o IPI é responsável por mais de $15 \%$ do total repassado para o FPM (CNM, 2017).

Quando considerados os municípios de médio porte, observam-se aumentos significativos em todos os anos analisados, principalmente, entre 2010 e 2014, com médias de 27\% e 20\% (ver Figura 02). Entre os determinantes dessa expansão, estão os recursos de transferências e as emendas parlamentares não previstas nos orçamentos iniciais. Citam-se os casos de Vale do Sol, cuja arrecadação cresceu 56,11\% em 2010, sendo $20 \%$ deste acréscimo apenas com o recurso de transferência de Convênio do Estado destinado aos Programas de Infraestrutura em Transporte (Acesso 471 - Daer).

Da mesma forma ocorreu com o município de Rio Pardo, que apresentou significativo crescimento, de 54,30\% em 2014 quando comparado ao ano anterior, decorrente do recebimento de transferências dos entes estadual e federal. Além daquele, Arroio do Tigre, em 2010, também registrou expressivo crescimento, na ordem de 26,13\%; deste crescimento, $10 \%$ originou-se do ingresso de receitas de capital que não estavam previstas no orçamento inicial, consolidadas em emendas parlamentares e convênios realizados com a União e Estado.

Ainda sobre os municípios de porte médio, por possuírem suas bases arrecadatórias diversificadas, observaram-se pequenas variações nas transferências governamentais e decréscimos na arrecadação anual. As menores médias de crescimento foram de 7,78\%, em 2015 e de 8,48\%, em 2012, respectivamente, nos municípios de Vale do Sol e Vera Cruz.

Tais resultados sugerem que os efeitos das políticas macroeconômicas de desoneração fiscal impactaram menos os municípios do segundo grupo comparativamente aos do primeiro, cuja população é menor e a restrição orçamentária maior. Conforme verificado nas Figuras 01 e 02, 2015 foi o ano em que as receitas apresentaram retração para os municípios menores, diferentemente dos municípios maiores, porte médio, os quais apresentaram crescimento, embora pequeno. 
Figura 2 - Evolução da arrecadação dos municípios de médio e grande porte, no período de 2009 a 2016 , em \%

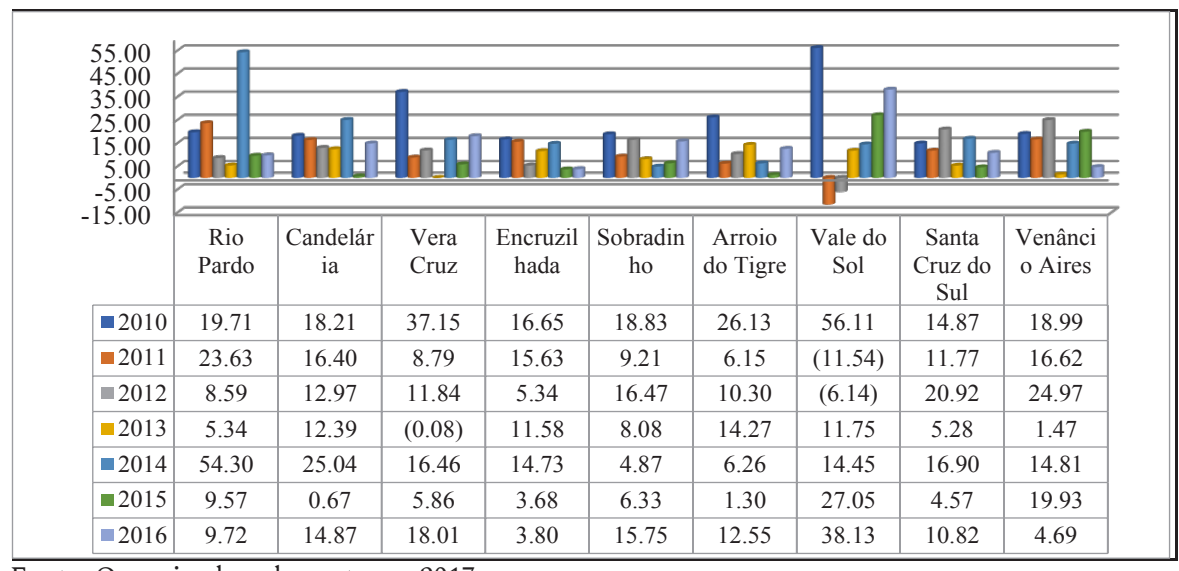

Fonte: Organizada pelos autores, 2017.

Contudo, o reflexo da estagnação das receitas deve ser verificado com cautela na execução das despesas públicas, contrariando o movimento de expansão dos últimos 12 anos. Em 2015, a despesa com pessoal manteve-se praticamente no mesmo patamar do ano anterior, repondo apenas o crescimento inflacionário. Para equilibrar seus orçamentos, $70 \%$ dos municípios reduziram gastos com custeio, sendo que desde 2004 não havia registros de queda generalizada nesta área.

Complementando a análise, quanto aos municípios de grande porte, destaca-se a consistente base arrecadatória, com destaque para o ICMS, que obteve as maiores médias no período de 2009 a 2016. Todavia, a estrutura fiscal dos municípios mostra-se diferenciada, enquanto que Santa Cruz do Sul, cuja população aproxima-se de 130.000 habitantes, apresenta receitas próprias como uma importante fonte de arrecadação, com a média de 13,86\%, superior às transferências do FPM (média de 11,79\%), Venâncio Aires, com cerca de 70.000 habitantes, tem nas transferências do FPM e no ICMS a principal fonte de arrecadação, as quais representaram o dobro da média da arrecadação própria (ver Tabela 1).

Além dessas receitas, destacam-se as outras transferências correntes dos entes estaduais e federais, cuja participação atingiu média de 30 e 39\%, respectivamente. Essas transferências compõem-se de recursos para Sistema Único de Saúde (SUS), para Assistência Social (FNAS) e para o desenvolvimento e manutenção da Educação infantil e básica.

Tabela 1 - Média das arrecadações dos municípios de grande porte entre 2009 a 2016

\begin{tabular}{lcc}
\hline \multicolumn{1}{c}{ Média do Período } & Santa Cruz do Sul & Venâncio Aires \\
\hline Receita Própria Tributária & 13,86 & 9,5 \\
ICMS & 30,34 & 19,37 \\
FPM & 11,79 & 17,64 \\
Outras Receitas Tributárias & 3,91 & 3,87 \\
Receita de Contribuições & 1,51 & 3,76 \\
Receita Patrimonial & 1,00 & 8,22 \\
Receita de Serviços & 0,01 & 0,15 \\
Outras Transferências Correntes & 39,09 & 30,47 \\
Outras Receitas Correntes & 3,20 & 2,83 \\
Receitas de Capital & 4,80 & 7,34 \\
Receita Corrente Intra-Orçamentária & 0,00 & 7,01 \\
Dedução da Receita (-) & $-9,91$ & $-10,17$ \\
\hline Total & $100 \%$ & $100 \%$ \\
\hline
\end{tabular}

Fonte: Organizada pelos autores, 2017 
As transferências constitucionais têm a finalidade de ratear a receita proveniente da arrecadação de impostos entre os entes federados como um mecanismo basilar para amenizar as desigualdades regionais e promover o equilíbrio socioeconômico entre estados e municípios. Além do FPM, tem um papel importante na equalização o FUNDEB, pois os recursos deste fundo contribuíram para equalizar a maioria das necessidades fiscais na área da educação. A transferência do SUS atua na equalização da necessidade associada à população em situação de pobreza, cujas disparidades são negligenciadas e até agravadas pelas demais transferências. Esses recursos têm papel fundamental nas arrecadações municipais e permitem aliviar a pressão orçamentária do governo local, sobremaneira naqueles menos estruturados (BAIÃO 2013).

Outro aspecto observado está na forma de crescimento das receitas nos anos analisados, que se originaram praticamente das receitas de capital, muitas vezes não previstas nos orçamentos municipais. Essa situação permite ratificar que o modelo arrecadatório dos municípios não tem conseguido expandir as receitas próprias de forma consistente, sobremaneira dos menores (pequeno porte) que ficam assim mais suscetíveis à conjuntura político-econômica e ao movimento das transferências constitucionais.

Seguindo esta linha, Silva e Calegari (2015) evidenciam que, dada a precária estrutura organizacional dos municípios menores, faz-se importante desenvolver iniciativas como o Programa de Modernização da Administração Tributária e dos Setores Sociais Básicos (PMAT) que, desde sua criação em 1997, busca amparar os esforços para ampliar as receitas próprias e garantir maior autonomia aos municípios de forma a possibilitar aumento do nível de eficiência fiscal e o desempenho das políticas públicas.

Diante do exposto, as evidências indicam que os municípios de pequeno porte encontram-se mais condicionados as transferência do FPM, evoluíram pouco no período analisado e investiram montantes decrescentes em novos projetos, sobremaneira, em função da queda da arrecadação. Estes resultados demonstram a necessidade de desenvolver ações que visam incrementar as receitas tributárias, em específico as próprias e que, consequentemente, resultem em melhorias na oferta de bens e serviços públicos.

\section{Análise da dependência ao recurso do FPM}

O estudo da Confederação Nacional de Municípios (2017) demonstrou que o FPM sofre uma das maiores instabilidades de sua história, com retrações seguidas nos valores dos repasses, como consequência dos efeitos da crise, caso do enfraquecimento do comércio, do aumento da inflação e do desemprego e, consequentemente, da baixa taxa de arrecadação de impostos. Com tantos imprevistos, os municípios, cujo FPM é a principal fonte de recursos, têm encontrado sérias dificuldades pela falta de disponibilidade financeira para atender as demandas locais, que, ao contrário, crescem de forma acelerada.

Analisando o COREDE Vale do Rio Pardo, no período de 2009 a 2016, corrobora-se que as transferências do FPM consistem na principal fonte de receita, sobretudo para aqueles municípios de pequeno porte, que possuem uma reduzida participação da arrecadação tributária própria (TCE/RS, 2016; PORTAL DA TRANSPARÊNCIA DOS MUNICÍPIOS, 2017). Esses resultados estão em linha com os apresentados por Massardi e Abrantes (2016), os quais analisaram os municípios de Minas Gerais, entre os anos de 2004 a 2009 e constataram a dependência dos municípios em relação aos recursos de transferência do FPM está ligada ao tamanho do município.

Na mesma linha, Vescovi Júnior (2003) expôs que os municípios que possuem média e alta dependência do FPM possuem uma população média entre 3.202 e 11.406 habitantes, respectivamente; em compensação, os municípios que foram classificados como de baixa dependência do FPM possuem em média população de 104.725 habitantes. Essa situação é explicada por Santos e Santos (2014) como sendo resultado do baixo poder de arrecadação de seus tributos e da predominância da atividade rural dos pequenos municípios.

Este cenário de dependência é corroborado pelas evidências dos municípios de pequeno porte. Em 2009, foi registrada a maior média de vinculação do FPM, $43,36 \%$ e, no ano seguinte, 2010 , a menor média, 36,97\%. Justifica-se essa grande diferença, pois 2009 foi o ano em que os municípios experimentaram os maiores reflexos da crise econômica, registrando queda generalizada das receitas, inclusive do FPM. Já em 2010, os munícipios receberam a maior soma de recursos de emendas parlamentares dos entes federais e estaduais, como também recursos para os desastres ambientais ocorridos na região, elevando as demais fontes de receita e reduzindo a representatividade do FPM.

Analisando temporalmente, verifica-se que os menores municípios em número de habitantes são os que apresentam maior grau de dependência aos recursos do FPM, atingindo até $70 \%$ do total da receita arrecadada, como também, que essa dependência, em geral, tem sido crescente. A Figura 03 apresenta os municípios de pequeno porte, em ordem crescente de população (da direita para esquerda), o que permite observar a vinculação constante destes municípios. Lagoa Bonita do Sul, Herveiras, Tunas e Vale Verde, os menores em termos populacionais, possuem alta dependência aos recursos do FPM, dado que, em vários exercícios do período analisado, apresentam nível de dependência superior a $50 \%$ de sua receita orçamentária total arrecadada. 
A média de vinculação ao FPM dos municípios deste grupo foi de $40,89 \%$, resultado, contudo, que expõem extremos. Enquanto Pântano Grande apresentou relação média de 24\%, em Lagoa Bonita do Sul a média foi de 65,83\%, o maior nível, variando entre 61,81\% (2014) e 70,53\% (2011). Em seguida, encontra-se o município de Herveiras, com média de $55,02 \%$ de dependência, variando entre $47,06 \%$ (2010) e 58,97\% (2016). Na terceira e quarta posições estão os municípios de Tunas e Vale Verde, com médias de $46 \%$ atreladas ao FPM. Além de possuírem pequenos contingentes populacionais, esses municípios são também os que possuem o menor PIB.

Por outro lado, com menor dependência deste grupo, além de Pantano Grande, encontram-se os municípios de Boqueirão do Leão, Segredo e Passo do Sobrado, cujo nível médio de vinculação do FPM em relação à receita orçamentária foi de 33\%, enquadrando-se no nível médio de dependência, com diferença de oito pontos percentuais. Esses municípios possuem característica diferenciada dos demais desta mesma faixa, tendo variada atividade econômica, com participação expressiva na arrecadação de ICMS (ver Figura 3), tributo que representou mais de $20 \%$ da arrecadação anual nos anos analisados.

Figura 3 - Nível de dependência do FPM dos municípios de pequeno porte, no período de 2009 a 2016, em \%

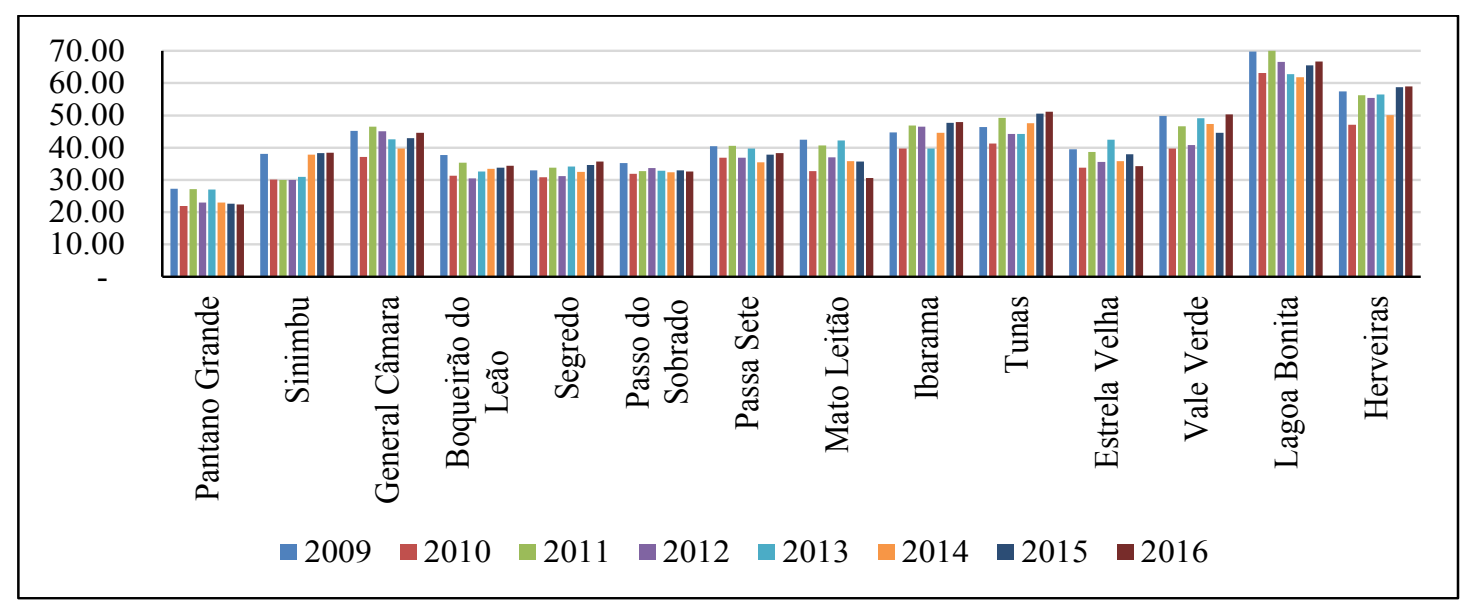

Fonte: Organizada pelos autores, 2017.

Destaca-se ainda que, em Pântano Grande, encontram-se grandes empresas dos setores agrícola, cal e calcário, as quais contribuem à composição do valor adicionado, caso da Cooperativa Agrícola Mista General Osório LTDA (Cotribá), Universal de Calcário Ltda, Cooperativa Triticola de Espumoso (Cotriel), Irmãos Cioccari e Cia Ltda (Fida), Indústria de Calcário de Caçapava do Sul Ltda (Inducal).

Quanto à evolução nominal na arrecadação do FPM, verifica-se crescimento constante para o grupo dos menores municípios, com média de 10\% do ano, entre 2010 a 2016 (ver Figura 4). No entanto, nos anos de 2011 e 2016, o crescimento foi superior à média, com evolução entre $23 \%$ e $16 \%$, respectivamente.

Figura 4 - Evolução na arrecadação do FPM dos municípios de pequeno porte, no período de 2009 a 2016, em \%

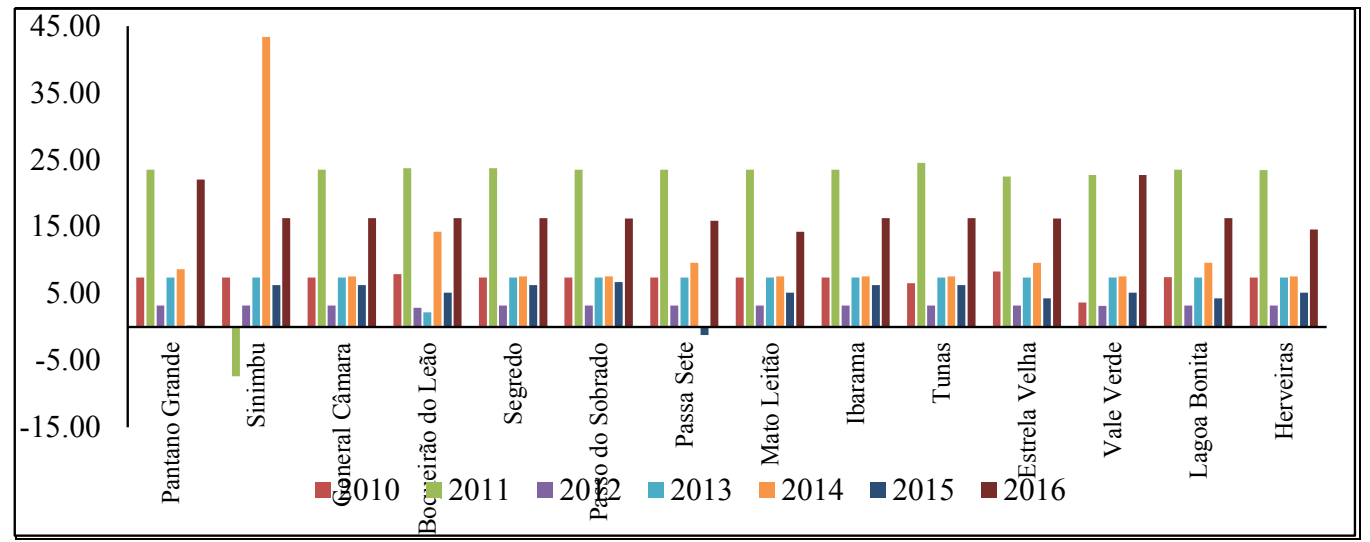

Fonte: Organizada pelos autores, 2017. 
O acréscimo em 2011 originou-se dos quatro créditos extras recebidos pela União relativos à Classificação por Estimativa das receitas de IR e do IPI, prevista na Portaria MF n. 232, de 20 de maio de 2009, e, ainda, pela baixa arrecadação verificada no ano anterior. Este aumento também foi verificado por Larsen et al. (2012) quando analisaram os dados do município de Pareci Novo/RS, constatando que as receitas correntes de FPM em 2010 e 2012 foram inferiores às receitas previstas, porém, em 2011, foi maior do que o valor previsto.

Já o acréscimo verificado em 2016 pode ser explicado por meio da Emenda Constitucional n. 84 de 2014, que altera o art. 159 da Constituição Federal para aumentar a entrega de recursos pela União para o FPM, no percentual de 1\%. Essa parcela foi integralizada de modo parcial, sendo a metade no primeiro decêndio do mês de julho de 2015 e, a segunda, no mês de julho do ano seguinte, 2016. Ainda, neste ano, os municípios foram surpreendidos positivamente com o recebimento dos recursos da repatriação e regularização de ativos (bens, valores, créditos e direitos) mantidos no exterior e não declarados, conforme Lei n. 13.254/2016 alterada pela Lei n. 13.428/2017.

Salienta-se também a evolução da arrecadação do FPM de Sinimbu que apresentou crescimento de $43,4 \%$ em 2014, expansão decorrente da alteração na previsão populacional, conforme Decisão Normativa TCU n. 133, de 27 de novembro de 2013, que alterou o número de habitantes, passando para o coeficiente do FPM de 0,6\% para $0,8 \%$. Esta alteração foi registrada apenas para Sinimbu, representando um acréscimo significativo de mais de $\mathrm{R} \$ 2$ milhões, comparando com os demais municípios do grupo que recebem montantes segundo o coeficiente de $0,6 \%$.

No que tange aos municípios de médio porte (em ordem crescente da direita para esquerda em termos populacionais), eles enquadram-se no nível médio de dependência, com o nível de dependência ao FPM variando entre as médias de $24 \%$ e $33 \%$. Quando comparado aos municípios de pequeno porte, a maior média do grupo dos menores municípios $(65,83 \%)$ foi o dobro da maior média daqueles de médio porte. Por outro lado, a menor média dos municípios intermediários $(24,20 \%)$ se equipara à menor média do grupo menos populoso, apresentada pelo município de Pantano Grande (24,33\%).

Detalhando os índices, observa-se que o menor nível de dependência do FPM em relação à receita orçamentária anual, considerando a média do período, foi encontrado em Vera Cruz, com 24,2\%, com variação entre 22,72\% (2010) e 25,8\% (2011). Em seguida, encontram-se os municípios de Candelária e de Encruzilhada do Sul, cujas médias no período foram de $26,12 \%$ e $26,20 \%$, respectivamente. De outro lado, os municípios que apresentaram maior grau de dependência foram Arroio do Tigre, com média no período de 33,1\%, seguido por Sobradinho, com média de 31,06\%.

Figura 5 - Nível de dependência do FPM dos municípios de porte médio, no período de 2009 a 2016, em \%

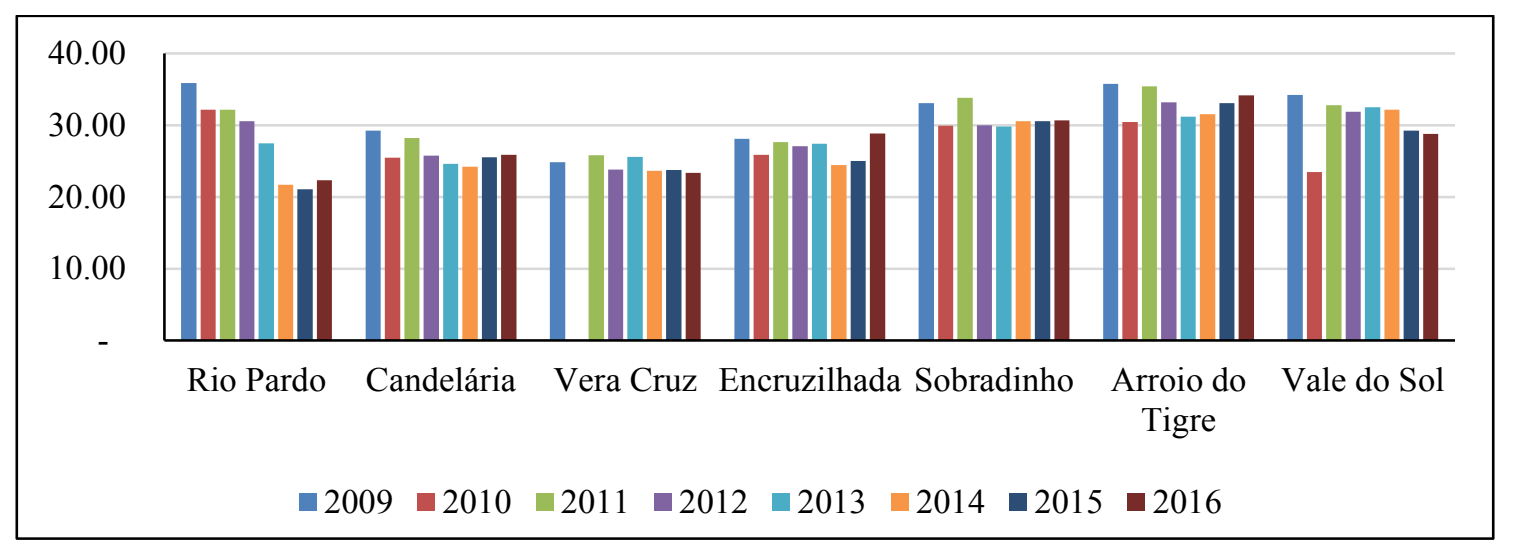

Fonte - Organizada pelos autores, 2017

Esta diferença de arrecadação pode ser explicada, conforme Santos e Santos (2014), pela população municipal, dado que quanto maior o contingente menor a dependência das transferências federais. Além disso, municípios maiores possuem atividade econômica variada e fortalecida, com produção industrial e serviços, como é o caso dos municípios de Candelária, Encruzilhada do Sul e Vera Cruz.

Entre os municípios, destaca-se Vera Cruz, que apresentou crescimento de 25,32\% em 2010, superior à média de $10 \%$ do período, e Candelária, em 2014, com acréscimo de $22 \%$. Esta evolução decorreu da alteração na previsão populacional, conforme Decisão Normativa TCU Plenário n. 024.957/2009-1, sendo o coeficiente do FPM de Vera Cruz acrescido de $1,2 \%$ para $1,4 \%$, representando um acréscimo de $3,24 \%$ na arrecadação total. Também, conforme Decisão Normativa TCU Plenário n. 030.131/2013-8, o município de Candelária, em 2014, teve elevação de dois pontos percentuais no índice de FPM, representando um acréscimo de mais de R $\$ 2$ milhões, correspondente a $3 \%$ no total de arrecadação total.

Em relação à evolução do FPM, os municípios de médio porte apresentaram crescimento, com destaque para 
os anos de 2011 e de 2016 (ver Figura 06). Essa expansão foi motivada, em 2011, pelos créditos recebidos da União relativos à Classificação por Estimativa das receitas de IR e IPI, prevista na Portaria MF n. 232 , de 20 de maio de 2009, conforme informações da CNM. Em 2016, além do recebimento integral da cota de 1\% de FPM (cota extra no mês de julho), houve recebimento extra dos recursos da repatriação e regularização de ativos (bens, valores, créditos e direitos) mantidos no exterior e não declarados, conforme Lei n. 13.254/2016 alterada pela Lei n. 13.428/2017 (CNM 2017).

Figura 6 - Evolução na arrecadação do FPM dos municípios de porte médio, no período de 2009 a 2016 , em \%

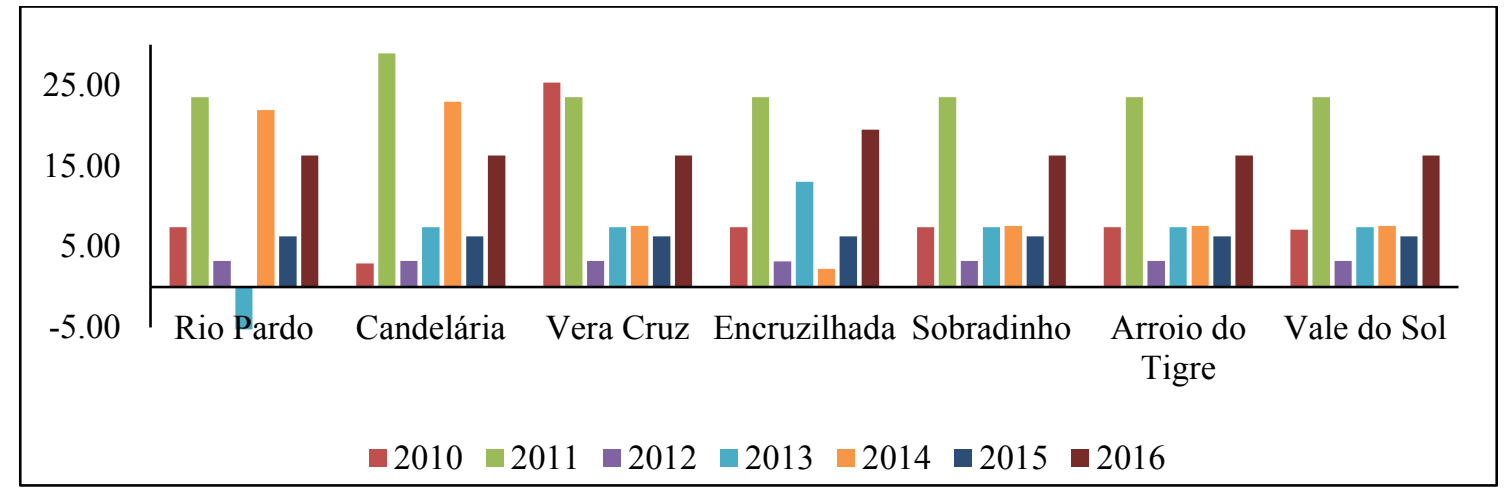

Fonte: Organizada pelos autores, 2017.

Complementando, os municípios mais populosos do COREDE, de grande porte, foram enquadrados ao nível de baixa dependência, com participação do FPM na receita orçamentária significativamente inferior aos demais, com variação média entre $12 \%$ e $18 \%$ (ver Figura 7). Venâncio Aires apresentou o maior nível de dependência do FPM, atingindo 20,78\% em 2015 e 19\% nos anos de 2009 e 2016, enquanto que em Santa Cruz do Sul, município mais populoso, o nível de vinculação do FPM/RO situou-se em 11,79\%, com pequena oscilação entre os anos de 2009 e 2016, com os limites encontrados nos de 2014 , de $10,63 \%$ e, de 2009 , de $13,32 \%$.

Estes municípios possuem características diferenciadas em termos de arrecadação, as quais estão baseadas na elevada capacidade tributária própria e em uma consistente arrecadação de ICMS, com médias bem superiores às médias do FPM. Venâncio Aires apresentou média de arrecadação do ICMS de 20\% ao ano, receita baseada nos setores industriais - fumageiras e indústrias de máquinas e implementos agrícolas, fogões e resfriadores, embalagens plásticas, calçados, vestuário esportivo, móveis - e na cultura e produção de erva mate. Além desses setores, o município é o maior produtor de leite da região (PETRY E SILVEIRA, 2017).

Figura 7 - Nível de dependência do FPM dos municípios de grande porte, no período de 2009 a 2016 , em \%.

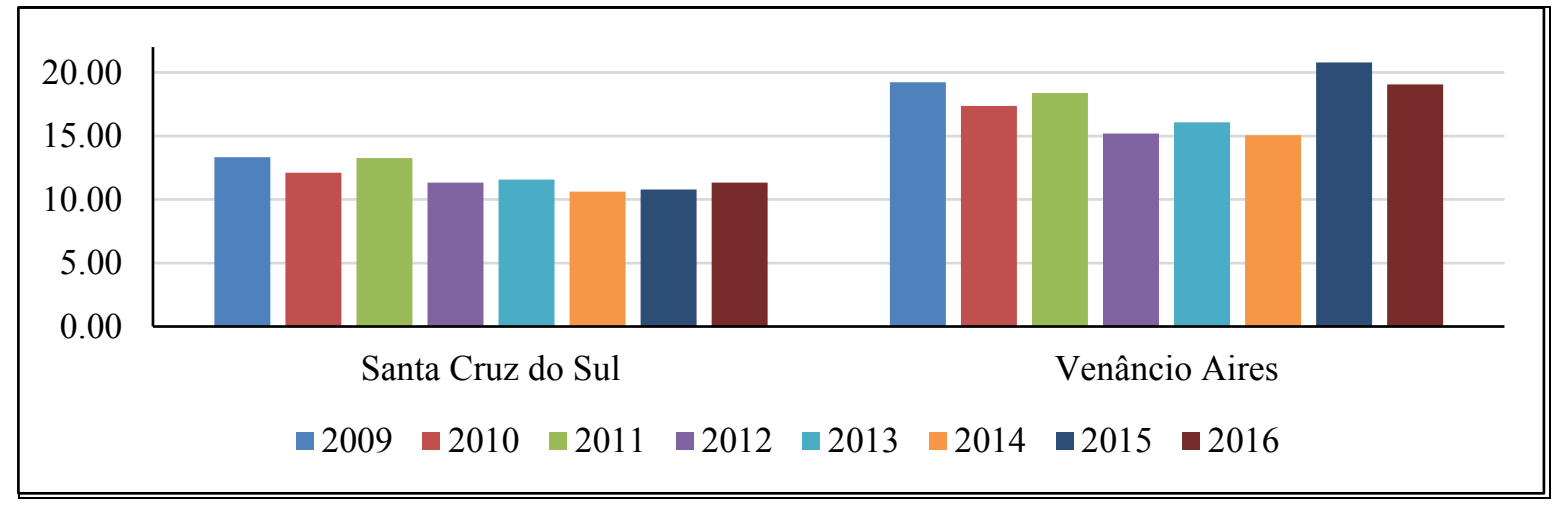

Fonte: Organizada pelos autores, 2017.

De igual forma, Santa Cruz do Sul apresentou média de arrecadação do ICMS elevada, superior a 30\%. Este resultado se refere, em grande medida, à atividade da indústria fumageira, tanto na produção quanto na exportação, como também às indústrias de alimentação, plástico e borracha. Outro setor importante para o município é o da prestação de serviço, tendo relevante participação a contribuição do setor educacional (faculdades e universidade).

Em relação à evolução do FPM, conforme Figura 08, destaca-se o crescimento nos anos de 2011 e de 2016, igual- 
mente ao registrado para os demais municípios. Resultados que tiveram como fatos geradores as mudanças legais, caso da ampliação da cota parte de transferências e da repatriação e regularização de ativos do exterior.

Figura 8 - Evolução na arrecadação do FPM dos municípios de grande porte, no período de 2009 a 2016, em \%

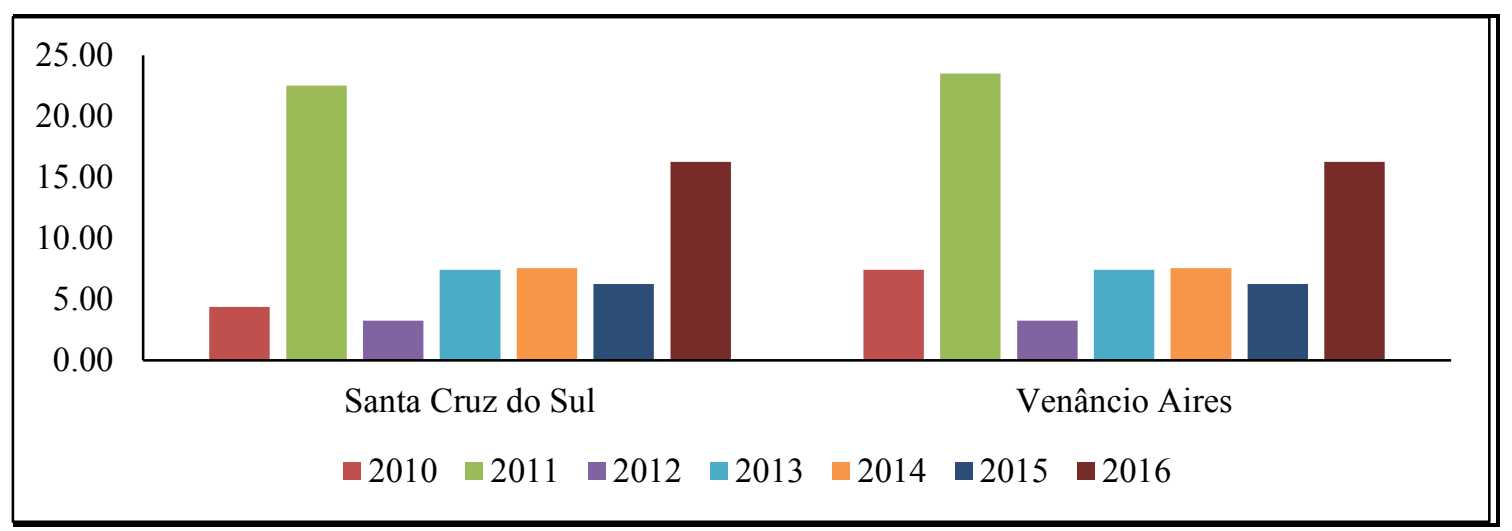

Fonte: Organizada pelos autores, 2017.

Sintetizando, o resultado do grau de dependência da arrecadação da transferência do FPM dos municípios do COREDE Vale do Rio Pardo corroborou os achados de Santos e Santos (2014) e Brito e Dias (2015), que constataram que a dependência de recursos de transferência varia de acordo com número de habitantes e com predominância de atividades econômicas. Conforme Tabela 2, o grupo menos populoso (pequeno porte), apresentou dependência média de $41 \%$, chegando a atingir nível alto de $70 \%$; já os municípios de médio porte apresentaram média de $28 \%$, classificando-se no nível médio de dependência, enquanto que para o grupo mais populoso (grande porte), a média de FPM/RO foi $15 \%$. Outra característica observada foi a maior variabilidade dos recursos de dependência do FPM nos municípios de pequeno porte.

Esse maior intervalo de dependência verificado nos municípios de pequeno porte pode ser explicado pelo fato de que FPM tem como principal indicador de transferência de recurso a faixa populacional. Lagoa Bonita do Sul, município com nível de alta dependência, apresentou a mesma arrecadação de FPM no período que os maiores em população do grupo, como Pantano Grande. Por outro lado, algumas receitas são arrecadadas conforme faixa populacional constante no sistema; na educação, com base no número de alunos matriculados na rede de ensino; no SUS, o número de pessoas atendidas nas unidades de saúde, e outras receitas, como ICMS, com base na renda produzida.

Tabela 2 - Análise comparativa do nível de dependência do FPM por grupos de municípios do COREDE Vale do Rio Pardo

\begin{tabular}{|c|c|c|c|c|}
\hline Grupos & Faixa populacional & $\begin{array}{c}\text { Nível de } \\
\text { Dependência }\end{array}$ & Média FPM & $\begin{array}{c}\text { Intervalo mín./máx. } \\
\text { FPM }\end{array}$ \\
\hline pequeno porte & $<10.000$ hab. & Médio/Alta & $41 \%$ & $24 \% / 70 \%$ \\
\hline médio porte & $\begin{array}{c}\text { entre } 10.000 \text { e } \\
50.000 \text { hab. }\end{array}$ & Média & $28 \%$ & $24 \% / 33 \%$ \\
\hline grande porte & $>50.000$ hab. & Baixa & $15 \%$ & $12 \% / 18 \%$ \\
\hline
\end{tabular}

Fonte: Organizada pelos autores, 2017.

$\mathrm{Na}$ mesma linha, o estudo de Massardi e Abrantes (2016) sobre os municípios do interior de Minas Gerais, constatou que a grande maioria possui nível médio de dependência superior a $50 \%$, indicando que os recursos do FPM representam a principal fonte de financiamento municipal, com destaque para os municípios com população inferior a 20.000 habitantes. A conclusão é corroborada por Tristão (2003), quando evidenciou que as transferências constitucionais, principalmente do FPM, representam em média $65 \%$ da receita total, ficando evidentes que a coluna vertebral das finanças públicas municipais são as transferências intergovernamentais.

Em relação à evolução na arrecadação do FPM, além do crescimento nominal dos recursos de transferências 
para todos os municípios e da ampliação da cota extra de 1\% e do recebimento extra dos recursos da repatriação e regularização de ativos do exterior, em 2016, alguns municípios apresentaram mudança na estrutura arrecadatória decorrente da alteração dos coeficientes de previsão populacional, conforme Decisão Normativa TCU. Aumentaram, com isso, suas arrecadações em 2010 e 2014, os municípios de Candelária, Sinimbu e Vera Cruz.

\section{Considerações finais}

Nos municípios são fornecidos bens e serviços, tanto públicos quanto privados, situação que torna estes entes federados mais sujeitos às pressões e anseios da sociedade. Por outro lado, as restrições orçamentárias têm se agravado, com as sucessivas crises econômicas, dificultado o equilíbrio fiscal e o atendimento das demandas locais. É neste cenário que o estudo se inseriu ao estudar o nível de dependência dos recursos de FPM e evolução orçamentária dos 23 municípios do COREDE Vale do Rio Pardo, com suas particularidades e similaridades.

Especificamente, analisaram-se a estrutura orçamentária dos municípios e o grau de dependência das transferências do FPM dos municípios do COREDE Vale do Rio Pardo, no período de 2009 a 2016. Para tanto, em função da heterogeneidade, os municípios foram classificados em grupos conforme faixa populacional: grande porte, com população superior a 50.000 habitantes; médio porte, com população entre 10 e 50.000 habitantes; e, por fim, pequeno porte, com população inferior a 10.000 habitantes.

Em termos de resultados, foi identificado que o nível de dependência de recursos de transferência varia de acordo com o número de habitantes e com predominância de atividades econômicas, dado que $92 \%$ dos municípios da amostra estão classificados no nível médio de dependência ao FPM, no intervalo de $24 \%$ a $50 \%$ de dependência. Os municípios de pequeno porte apresentaram a média de $41 \%$ de receita do FPM no período, chegando a atingir nível de 70\%, caso dos municípios de Lagoa Bonita do Sul e Herveiras, alta dependência; os municípios de médio porte apresentaram média de arrecadação do FPM de $28 \%$, também classificados no nível de dependência média; enquanto que, para os municípios de grande porte, onde estão apenas dois dos 23 municípios, a média foi de 15\%, correspondente a baixa dependência do FPM. Destaca-se também o elevado crescimento arrecadatório nos anos de 2010 e 2014, de receitas de transferências de capital, oriundas de emendas parlamentares, considerando serem anos eleitorais a nível estadual e nacional.

Salienta-se também que, tanto a oscilação no nível de dependência quanto nos valores repassados pelo FPM, haja vista a relação entre os valores orçados e os efetivamente repassados reduziram-se ao longo do período, reflexo da retração do Produto Interno Bruto e das crises econômica e fiscal. Além disso, para os municípios mais atrelados as transferências do FPM, a agricultura que se constitui como base da atividade econômica, implica em reduzido desempenho da arrecadação função da natureza dessa tributação.

Os resultados permitem elucidar a problemática norteadora do estudo - qual o nível de dependência dos recursos de transferência do FPM e qual a dinâmica orçamentária dos municípios do COREDE Vale do Rio Pardo - quando o FPM, principal fonte de receita de grande parte dos Municípios de pequeno e médio porte, não acompanhou o crescimento dos custos das prefeituras nos últimos anos, agravando a dificuldade financeira destes municípios. Logo, sugestiona-se que a arrecadação deve ser formulada a partir de política adotada pelo município, a partir de planejamento à ampliação das receitas próprias, mesmo que as evidências comprovem que quanto menor o município, maior a dependência as transferências do FPM, menor estrutura organizacional e capacitação de servidores e gestores. Também, são relevantes ações para modificar a disponibilidade de recursos fiscais municipais, influenciando a capacidade de formular e implementar políticas públicas no plano local.

Por fim, o estudo é amplo e não se exaure, pois abre possibilidades de novas investigações à análise da dependência de recursos de transferência dos entes federais e estaduais, principalmente em períodos de crise financeira, fiscal, econômica e/ou institucional. Da mesma forma, relacionar a arrecadação do FPM a outros agregados macroeconômicos, como o nível de endividamento e o gasto público, ampliará o entendimento dinâmica das finanças públicas dos entes locais. Ademais, quanto aos gestores, faz-se importante aprofundar discussões quanto ao marco legal que regulamenta os diversos fluxos de recursos que compõem o orçamento em nível local, dos recursos próprios e da discussão da redistribuição de recursos orçamentários entre as esferas de governo.

\section{Referências}

ABRÚCIO, Fernando Luiz. A coordenação federativa no Brasil: a experiência do período FHC e os desafios do governo Lula. Revista de Sociologia Política, v. 24, p. 41-67, jun. 2005.

BAIÃO, Alexandre. Lima. O papel das transferências intergovernamentais na equalização fiscal dos 
municípios brasileiros. Rio de Janeiro: Escola Brasileira de Administração Pública e de Empresas, Fundação Getúlio Vargas - FGV, 2013. 70 p. Dissertação apresentada à Escola Brasileira de Administração Pública e de Empresas.

BRASIL. Constituição Federal (1988). Constituição da República Federativa do Brasil. Brasília: Senado Federal, 2013.

BRASIL. Finanças: procedimento para otimizar a arrecadação municipal. Confederação Nacional de Municípios (CNM). Brasília: CNM, 2012.

BRITO, Horlânia de Sousa; DIAS, Ricjardeson Rocha. O Comportamento da Receita Pública Municipal: Um Estudo de Caso no Município de Parnaíba - PI. Revista de Gestão e Contabilidade da UFPI, [S.l.], v. 3, n. 1, p. p.130-146, dez. 2015. ISSN 2358-1735.Disponível em: http://www.ojs.ufpi.br/index.php/gecont/article/view/3466. Acesso em: 09 nov. 2017.

CONFEDERAÇÃO NACIONAL DE MUNICÍPIOS - CNM. Gestão Municipal: Projetos em Ação - Boas Práticas compartilhadas para as finanças municipais. Disponível em $<\mathrm{https} / / \mathrm{www} . \mathrm{cnm}$.org.br/cms/biblioteca_antiga/ Gest\%C3\%A3o\%20Municipal.\%20Projetos\%20em\%20A\%C3\%A7\%C3\%A3o\%20(2016).pdf> Acesso em 15 de fev. 2017.

CONFEDERAÇÃO NACIONAL DE MUNICÍPIOS - CNM. Gestão Municipal: FPM de 2016 foi salvo com recursos da repatriação. Disponível em https://www.cnm.org.br/cms/biblioteca/FPM\%20de\%202016\%20foi\%20 salvo \%20pelos\%20recursos\%20da\%20repatria\%E7\%E3o\%20(fevereiro\%20de\%202017).pdf Acesso em 01 mar. de 2017.

CONFEDERAÇÃO NACIONAL DE MUNICÍPIOS - CNM. Gestão Municipal: Projetos em Ação - Boas práticas compartilhadas para as finanças municipais. Brasília: CNM, 2015.

CONSUlTORIA, AEQUUS. Multicidades - Finanças dos Municípios do Brasil: 2017. Frente Nacional de Prefeitos, v. 12, p. 180, 2017. Disponível em: http://multimidia.fnp.org. br/biblioteca/publicacoes/item/476anuario-multi-cidades-2017 Acesso em 30 jan. 2017.

DA SILVA, Hudson Pacifico; CALEGARI, Tales Victor. Políticas públicas para ampliação da arrecadação tributária municipal: considerações sobre o programa de modernização da administração tributária e dos setores sociais básicos (PMAT). Rev. Temas de Administração Pública, v. 10, n. 1, 2015, p.45-66.

DE SOUSA BRITO, H.; DIAS, R. R. O comportamento da Receita Pública Municipal: um estudo de caso no Município de Parnaíba-PI. Revista de Gestão e Contabilidade da UFPI, v. 3, n. 1, p. p. 130-146, 2015.

EIDT, S. L.; DE LIMA, J. F. Descentralização tributária no Brasil: um pacto federativo para os Municípios, Estados e a União Federal. Redes, v. 12, n. 2, p. 257-270, 2008.

FEDERAÇÃO DAS ASSOCIAÇÕES DE MUNICÍPIOS DO RIO GRANDE DO SUL- FAMURS. Turno único é adotado em pelo menos 121 prefeituras gaúchas. Disponível em: http:// http://www.famurs.com.br/noticias/ turno-unico-e-adotado-em-pelo-menos-121-prefeituras-gauchas (2016) Acessado em 15. dez. 2016.

FEDERAÇÃO DAS ASSOCIAÇÕES DE MUNICÍPIOS DO RIO GRANDE DO SUL- FAMURS. Impacto da queda do FPM e ICMS nos municípios gaúchos. Disponível em: http://www.famurs.com.br/notas tecnicas/ impacto-da-queda-do-fpm-e-icms-nos-municipios-gauchos-2015. Acessado em 25. mai. 2016.

FEDERAÇÃO DAS ASSOCIAÇÕES DE MUNICÍPIOS DO RIO GRANDE DO SUL- FAMURS. Municípios Gaúchos perdem R\$956 Milhões em 2015. Disponível em: http://www.famurs.com.br/noticias/municipiosgauchos-perdem-r-956-milhoes-em-2015/ Acessado em 25 mai. 2016.

FUNDAÇÃO DE ECONOMIA E ESTATÍSTICA - FEE. Perfil socioeconômico Corede Vale do Rio Pardo. Disponível em: http://www.fee.rs.gov.br/perfil-socioeconomico/coredes /detalhe/?corede=Vale+do+ Rio + Pardo. Acessado em 25. mai. 2016. 
INSTITUTO BRASILEIRO DE GEOGRAFIA E ESTATISTICA - IBGE. Cidades. Disponível em <https://cidades. ibge.gov.br/>. Acesso em 01 mar. de 2017.

FINANÇAS PÚBLICAS DO BRASIL - ÍNDICES FIRJAM DE GESTÃO FISCAL. Disponível em:< http://www. firjan.com.br/ifgf $>$. Acessado em 25. jan. 2017.

KOHAMA, Heilio. Contabilidade Pública: Teoria e Prática. 12.ed. São Paulo: Atlas, 2012.

LARSEN, Tríscia. et al. Transferências Constitucionais de Receitas Tributárias: Estudo no Município de Pareci Novo. XV Mostra de Iniciação Científica Pós-Graduação, Pesquisa e Extensão. Programa de Pós-Graduação em Administração da Universidade UCS.

LAKATOS, M. A.; MARCONI, E. M. Fundamentos de metodologia científica. 5.ed. São Paulo: Atlas, 2003.

LAKATOS, M. A.; MARCONI, E. M. Fundamentos de metodologia científica. 7.ed. São Paulo: Atlas, 2010.

MASSARDI, Wellington de Oliveira; ABRANTES, Luiz Antônio. Dependência dos municípios de Minas Gerais em relação ao FPM. Revista de Gestão, Finanças e Contabilidade, v. 1, n. 6, p. 173-187, 2016.

MATIAS-PEREIRA, Jose. (2012). Manual de gestão pública contemporânea. 4. ed. São Paulo: Atlas.

PRADO, S. Introdução conceitual e visão geral do sistema. In: PRADO, Sérgio (Org.). Transferências Intergovernamentais a Federação Brasileira: avaliação e alternativas de reforma. Rio de Janeiro: Fórum Fiscal dos Estados Brasileiros, Caderno n. 6, v. 2, 2007.

PETRY, H. Á.; SILVEIRA, R. L. L. Plano estratégico de desenvolvimento regional do Vale do Rio Pardo (20152030). Santa Cruz do Sul: EDUNISC, 2017.

RIO GRANDE DO SUL. Tribunal de Contas do Estado. Orientação do Tribunal de Contas para gestores. Porto Alegre: TCE/RS. 2014.

RIO GRANDE DO SUL. Diagnóstico sobre a estrutura e a logística da administração tributária municipal. Disponível em: < http://www1.tce.rs.gov.br/portal/page/portal/tcers/publicacoes/ estudos/estudos_pesquisas/adm_ trib_municipal/Diagnostico_admin_tribut_\%20municipal.pdf >. Acessado em 25. mai. 2016.

REZENDE, Fernando. Os Desafios do Federalismo Fiscal. In: REZENDE, F.. (Org.). Desafios do Federalismo Fiscal. Rio de Janeiro: FGV Editora, 2006.

SANTOS, K. G. B.; SANTOS, C. E. R. Dependência Municipal das Transferências do Fundo de Participação dos Municípios: uma análise para os municípios do Sul da Bahia entre 2008 e 2012. Anais da IV Semana do Economista, v. 7, 2014.

SILVA, Hudson Pacifico; CALEGARI, Tales Victor. Políticas públicas para ampliação da arrecadação tributária municipal: considerações sobre o Programa de Modernização da Administração Tributária e dos Setores Sociais Básicos (PMAT). Rev. Temas de Administração Pública, v. 10, n. 1, 2015, p.45-66.

SILVA, Lino Martins da. Contabilidade Governamental: um enfoque administrativo. 9.ed. São Paulo: Editora Atlas, 2009.

TEIXEIRA, E. C. O papel das políticas públicas no desenvolvimento local e na transformação da realidade. Salvador: AATR, 2002.

TEIXEIRA, J. R. B. O atual desequilíbrio no sistema de repartição de receitas tributárias. Estudos da Consultoria Legislativa da Câmara dos Deputados, 2005.

TRISTÃO, José Américo Martelli. A Administração Tributária dos Municípios Brasileiros: uma avaliação do desempenho da arrecadação. São Paulo: EAESP/FGV, 2003. 172 p. Tese de doutorado apresentada ao Curso de Pós-Graduação da EAESP/FGV. 